\title{
The Efficacy of Device Designs (Mono-block or Bi-block) in Oral Appliance Therapy for Obstructive Sleep Apnea Patients: A Systematic Review and Meta-Analysis
}

\author{
Hiroyuki Ishiyama ${ }^{1, *}$, Daichi Hasebe ${ }^{2}$, Kazumichi Sato ${ }^{3}{ }^{1}$, Yuki Sakamoto ${ }^{4}$, \\ Akifumi Furuhashi ${ }^{5}$, Eri Komori ${ }^{6}$ and Hidemichi Yuasa ${ }^{7}$ \\ 1 Orofacial Pain Management, Graduate School of Medical and Dental Sciences, Tokyo Medical and Dental \\ University (TMDU), 1-5-45 Yushima Bunkyo-ku, Tokyo 1138510, Japan \\ 2 Division of Reconstructive Surgery for Oral and Maxillofacial Region, Department of Tissue Regeneration \\ and Reconstruction, Niigata University Graduate School of Medical and Dental Sciences, 2-5274 \\ Gakkocho-Dori, Cyuo-ku, Nigata-shi, Nigata 9518514, Japan \\ 3 Department of Oral Medicine, Oral and Maxillofacial Surgery, Tokyo Dental College, \\ 5-11-13 Sugano Ichikawa-shi, Chiba 2728513, Japan \\ 4 Department of Oral Surgery, Hironokogen Hospital, 3-1-1 Kitayamadai Nishi-ku Kobe-shi, \\ Hyogo 6512215, Japan \\ 5 Department of Oral and Maxillofacial Surgery, Aichi Medical University, 1-1 Yazakokarimata Nagakute-shi, \\ Aichi 4801103, Japan \\ 6 Division of Medicine for Function and Morphology of Sensor Organ, Dentistry and Oral Surgery, \\ Osaka Medical College, 2-7 Daigaku-machi Takatsuki-shi, Osaka 5698686, Japan \\ 7 Department of Oral and Maxillofacial Surgery, National Hospital Organization Toyohashi Medical Center, \\ 50 Imure-chou Aza Hamamichi-Ue, Toyohashi-shi, Aichi 4408510, Japan \\ * Correspondence: h.ishiyama.rpro@tmd.ac.jp; Tel.: +(81)-3-5803-4981
}

Received: 10 August 2019; Accepted: 25 August 2019; Published: 31 August 2019

\begin{abstract}
Oral appliance $\left(\mathrm{OA}_{\mathrm{m}}\right)$ therapy has demonstrated efficacy in treating obstructive sleep apnea (OSA). The aim of this systematic review was to clarify the efficacy of device designs (Mono-block or Bi-block) in $\mathrm{OA}_{\mathrm{m}}$ therapy for OSA patients. We performed a meta-analysis using the Grading of Recommendations, Assessment, Development, and Evaluation (GRADE) system. Two studies (Mono-block $\mathrm{OA}_{\mathrm{m}}$ versus Bi-block $\mathrm{OA}_{\mathrm{m}}$ ) remained eligible after applying the exclusion criteria. When comparing Mono-block $\mathrm{OA}_{\mathrm{m}}$ and Bi-block $\mathrm{OA}_{\mathrm{m}}$, Mono-block $\mathrm{OA}_{\mathrm{m}}$ significantly reduced the apnea-hypopnea index (2.92; 95\% confidence interval $(95 \% \mathrm{CI}), 1.26$ to $4.58 ; p=0.0006)$, and patient preference for Mono-block $\mathrm{OA}_{\mathrm{m}}$ was significantly higher $(2.06 ; 95 \% \mathrm{CI}, 1.44$ to 2.06 ; $p<0.0001)$. Lowest $\mathrm{SpO}_{2}$, arousal index, non-REM stage 3, sleep efficiency, Epworth Sleepiness Scale (ESS), Snoring Scale, and side effects were not significantly different between the two groups (lowest $\mathrm{SpO}_{2}$ : $-11.18 ; 95 \% \mathrm{CI},-26.90$ to $4.54 ; p=0.16$, arousal index: $4.40 ; 95 \% \mathrm{CI},-6.00$ to $14.80 ; p=0.41$, non-REM stage 3: $-2.00 ; 95 \% \mathrm{CI},-6.00$ to $14.80 ; p=0.41$, sleep efficiency: $-1.42,95 \% \mathrm{CI},-4.71$ to $1.86 ; p=0.40$, ESS: $0.12 ; 95 \% C I,-1.55$ to $1.79 ; p=0.89$, Snoring Scale: $0.55 ; 95 \% C I,-0.73$ to $1.83, p=0.55$, side effects: $1.00,95 \% \mathrm{CI}, 0.62$ to $1.61, p=1.00)$. In this systematic review, the use of Mono-block OAm was more effective than Bi-block $\mathrm{OA}_{\mathrm{m}}$ for OSA patients.
\end{abstract}

Keywords: obstructive sleep apnea; oral appliance; systematic review; mono-block; bi-block 


\section{Introduction}

Obstructive sleep apnea (OSA) is a disease where the upper airway narrows or collapses repeatedly during sleep [1-4]. Anatomical factors of the upper airway and decompensation due to neuromodulation have been reported as the main causes of OSA [3,4]. In particular, obesity and micrognathia worsen the anatomical balance around the throat, increase pharyngeal obstruction, and are highly involved in the onset of OSA [5].

Oral appliance (OA) therapy is a treatment option for OSA [6]. Among the different appliances, mandibular advancement-type oral appliances $\left(\mathrm{OA}_{\mathrm{m}}\right)$ are mainly used. Wearing an $\mathrm{OA}_{\mathrm{m}}$ will pull the lower jaw forward and cause an expansion of the upper airway and oral cavity volume, thus preventing upper airway obstruction during sleep [7]. $\mathrm{OA}_{\mathrm{m}}$ are outstanding in their simplicity, economic efficiency, and portability, and recent reports show the beneficial effects of $\mathrm{OA}_{\mathrm{m}}$ even for severe cases of OSA $[8,9]$. An American Academy of Sleep Medicine (AASM) and American Academy of Dental Sleep Medicine (AADSM) clinical practice guideline recommends that sleep physicians consider the prescription of oral appliances, rather than no treatment, for adult patients with OSA who are intolerant of continuous positive airway pressure (CPAP) therapy or prefer alternate therapy [10].

There are various types of $\mathrm{OA}_{\mathrm{m}}$ devices [11]. However, most fall under one of two major designs: Mono-block and Bi-block types. As for Mono-block $\mathrm{OA}_{\mathrm{m}}$, since both the upper and lower jaw are fixed in place by the same device, jaw movement is restricted, leading to a sense of constraint during sleep. Further, there are many cases in which the anteroposterior position of the lower jaw cannot be easily adjusted. On the other hand, the Bi-block $\mathrm{OA}_{\mathrm{m}}$ has separate constructions for the upper and lower jaws and is equipped with connectors or attachments that advance the mandible. The lower jaw can be opened and moved sideways, resulting in a reduced sense of constraint and discomfort for the patient. The Bi-block $\mathrm{OA}_{\mathrm{m}}$ has a device that completely separates the upper and lower jaws, and a movable device that cannot completely separate the upper and lower jaws. The main feature of the Bi-block $\mathrm{OA}_{\mathrm{m}}$ is the ease of anteroposterior position adjustment of the lower jaw by means of a screw or connector built into the device. However, the treatment principle of expanding the upper airway by moving the lower jaw forward is the same in Mono-block $\mathrm{OA}_{\mathrm{m}}$ and Bi-block $\mathrm{OA}_{\mathrm{m}}$.

Although there are several systematic reviews (SRs) on $\mathrm{OA}_{\mathrm{m}}$ designs, a decisive conclusion as to which design is most effective for OSA treatment has not yet been reached. Therefore, in this systematic review, we extracted research results from past comparative studies of Mono-block $\mathrm{OA}_{\mathrm{m}}$ and Bi-block $\mathrm{OA}_{\mathrm{m}}$ (or similar designs), conducted a meta-analysis, and evaluated each design according to its OSA treatment efficacy. If one type was superior to the other, we evaluated the different designs to figure out the most effective design of that type. Our meta-analysis was performed using the Grading of Recommendations Assessment, Development, and Evaluation (GRADE) system [12,13].

\section{Materials and Methods}

This SR was performed following the PRISMA (Preferred Reporting Items for Systematic Reviews and Meta-Analyses) guidelines [14]. The protocol for this review was registered with the international prospective register of systematic reviews (PROSPERO) with the registration number CRD42019131303.

\subsection{Eligibility Criteria}

For this review, we referenced studies using $\mathrm{OA}_{\mathrm{m}}$ on OSA patients aged 18 years and above. When selecting studies for this review, the following criteria regarding the $\mathrm{OA}_{\mathrm{m}}$ had to be fulfilled: (1) the device was custom-made by creating a dental impression of the lower jaw for every patient, (2) the $\mathrm{OA}_{m}$ design was classified only as Mono-block and Bi-block types, and (3) titration of the $\mathrm{OA}_{\mathrm{m}}$ (including adjustment) was performed. Further, in order to comprehensively evaluate the influence of the structure of the $\mathrm{OA}_{\mathrm{m}}$, we did not establish any restrictions regarding the layout, material, thickness, or detailed design of $\mathrm{OA}_{\mathrm{m}}$ (type of connector used in Bi-block, presence of air vents in Mono-block, etc.). Another criterion for the inclusion of studies was the evaluation of diagnostic and therapeutic OSA 
treatment efficacy through either polysomnography (PSG) or Out of Center Sleep Testing (OCST). We excluded studies that included patients under the age of 18 years and patients with other coexisting sleep disorders, studies in which ready-made devices were used, and studies in which results were achieved by securing the tongue in a forward position through tongue retaining devices.

\subsection{Literature Search}

The searches were performed using the following databases: MEDLINE, Cochrane Central Register of Controlled Trials (CENTRAL), and Igaku Chuo Zasshi (Ichushi-Web). In the literature search, there were no restrictions on the year or language published. We selected only randomized controlled trials (RCTs) in the design of the $\mathrm{OA}_{\mathrm{m}}$, detailing the comparison of the Mono-block to the Bi-block or similar designs. Prospective and retrospective non-randomized clinical studies, case reports/case series, conferences abstracts, and reviews were excluded. A search strategy is shown in Figure 1 and the final literature search was conducted and completed on 27 April 2019. When searching, if an unpublished article such as a paper on conference proceedings was found, we investigated whether or not it was published later.

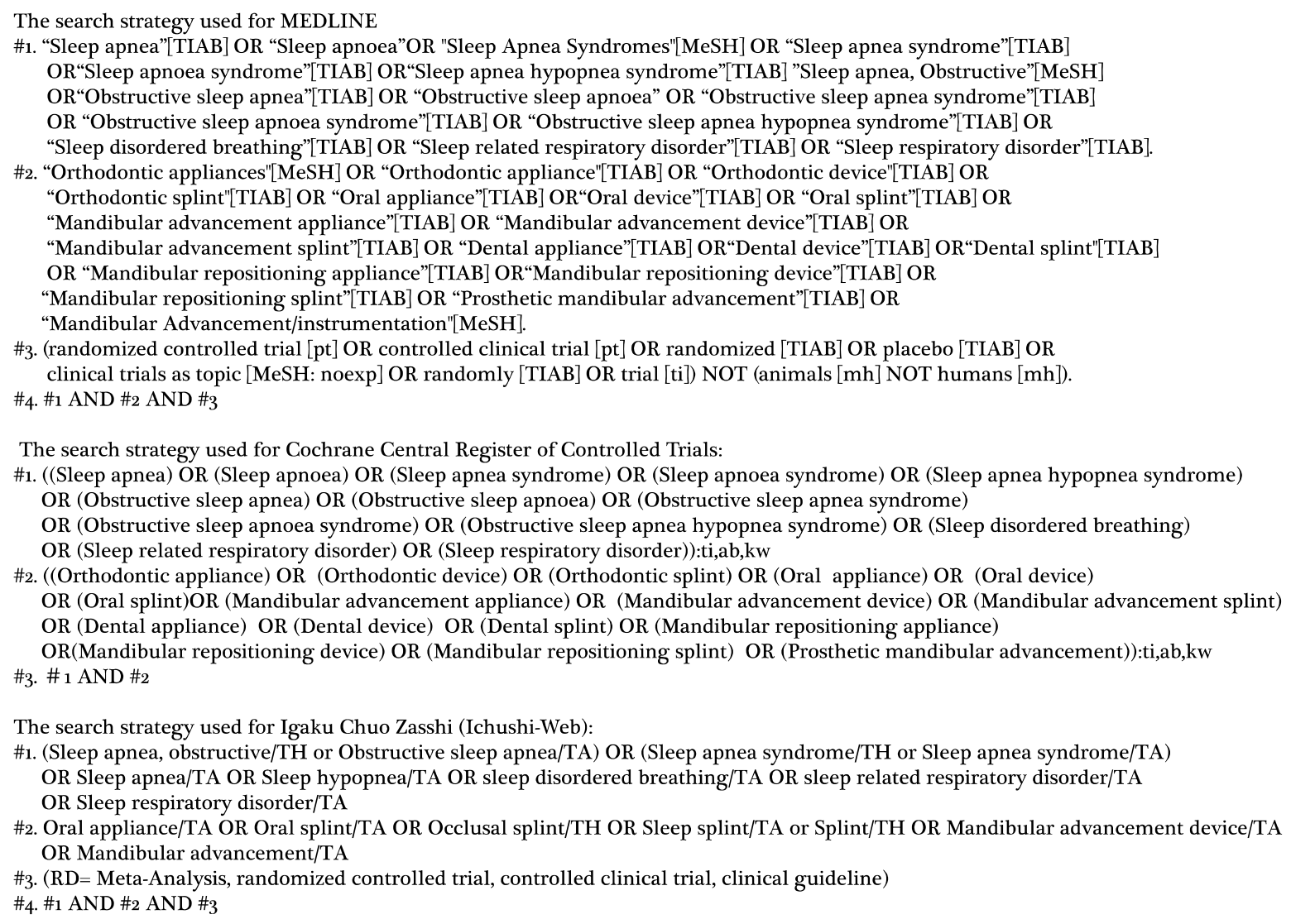

Figure 1. The search strategy used in this systematic review.

\subsection{Study Selection Procedure}

Eligible studies were selected in two phases. In the first phase, two authors independently screened the titles and abstracts. In the second phase, the full texts of all potentially eligible studies identified during the first phase were independently reviewed by two authors. During the full-text assessment, irrelevant studies were excluded based on the inclusion and exclusion criteria. When the selection differed between the two authors, we added a third author and solved the issue by discussion. 


\subsection{Data Extraction}

Data were extracted independently by three authors. The important information collected was the author name, year of publication, study design, type of device, number of subjects and dropouts, mean age, body mass index (BMI), mean baseline apnea-hypopnea index (AHI), follow-up periods, and study outcome. The extracted results included values for both before and after the $\mathrm{OA}_{\mathrm{m}}$ treatment. The primary outcomes were mortality rates and cardiovascular events, and surrogate outcomes were as follows: (1) treatment effects: AHI (including the respiratory disturbance index (RDI) and respiratory event index (REI)), lowest $\mathrm{SpO}_{2}$, arousal Index, sleep efficiency, sleep stage (non-REM stage 3: NREM stage 3), subjective daytime sleepiness (the Epworth Sleepiness Scale (ESS)), the loudness and effects (disturbance factor) of snoring (the Snoring Scale (SS)); (2) adherence (the duration of $\mathrm{OA}_{\mathrm{m}}$ usage at night and the number of days the $\mathrm{OA}_{\mathrm{m}}$ was used in the preceding week); (3) sleep-related quality of life (SF-36 Physical Component, SF-36 Mental Component); (4) hypertension: systolic blood pressure, diastolic blood pressure; (5) side effects: temporomandibular disorders (arthralgia or myalgia), tooth pain, occlusal changes (overbite, overjet), the changes of occlusal contact, the changes of bite force; and (6) patient preference. If the standard error of the mean (SEM) was reported for outcomes, the standard deviation (SD) was also calculated from the number of subjects in the study and the reported SEM.

\subsection{Data Synthesis and Statistical Analysis}

Meta-analyses were conducted using Review Manager (Nordic Cochrane Centre, Cochrane Collaboration, 2014 Copenhagen, Denmark) version 5.3 software by pooling data across studies for each outcome measure. The available case analysis was applied where data were missing. When multiple studies were combined, the risk ratio (RR) and the mean difference (MD) were used. The effectiveness was evaluated based on RR or MD and its $95 \%$ confidence interval (CI) in each study. A forest plot was constructed using the RR or MD of the outcome variable in each study. All analyses were performed using the fixed-effects model with results displayed as a forest plot.

\subsection{Quality Assessment of Included Studies}

The evaluation of the quality of evidence in this SR was performed using the Grading of Recommendations Assessment, Development, and Evaluation (GRADE) process [12]. The GRADE classification was downgraded by one level for each of the five factors we considered, which were study limitations, inconsistency, indirectness, imprecision, and publication bias. Seven authors judged whether the five factors were present for each outcome. The risk of bias of the studies included for this review were evaluated using the Cochrane Risk of Bias tool described in the Cochrane Handbook for Systematic Reviews of Intervention. A GRADE evidence profile was created using the GRADEpro software for each clinical domain and adverse events. The following definitions of the quality of the evidence were applied [13]: high quality (further research is very unlikely to change our confidence in the estimate of the effect), moderate quality (further research is likely to have an important effect on our confidence in the estimate of the effect and may change the estimate), low quality (further research is very likely to have an important effect and is likely to change the estimate), very low quality (we are very uncertain about the estimate).

\section{Results}

\subsection{Literature Search and Selection Results}

The PRISMA flow diagram is presented in Figure 2. Our selection of studies included 201 MEDLINE articles, 385 Cochrane Central Register of Controlled Trials (CENTRAL) articles, and 31 Igaku Chuo Zasshi (Ichushi-Web) articles. Excluding 158 duplicate articles, we screened the titles and abstracts of 459 articles. We then narrowed our selection down to 18 articles, of which 10 were excluded after confirming the eligibility of each articles (three duplicate articles, one non-RCT article, four articles 
without $\mathrm{OA}_{m}$ titration and with fixed mandibular position at the time of $\mathrm{OA}_{m}$ device fabrication, two cases of conference proceedings, one case in which the respective paper could not be located). Finally, seven articles were accepted (two articles of Mono-block $\mathrm{OA}_{\mathrm{m}}$ versus Bi-block $\mathrm{OA}_{\mathrm{m}}[15,16]$ and five articles of Bi-block $\mathrm{OA}_{m}$ versus Bi-block $\mathrm{OA}_{\mathrm{m}}$ [17-21]). We were not able to find any articles covering a comparison among Mono-block $\mathrm{OA}_{\mathrm{m}}$.

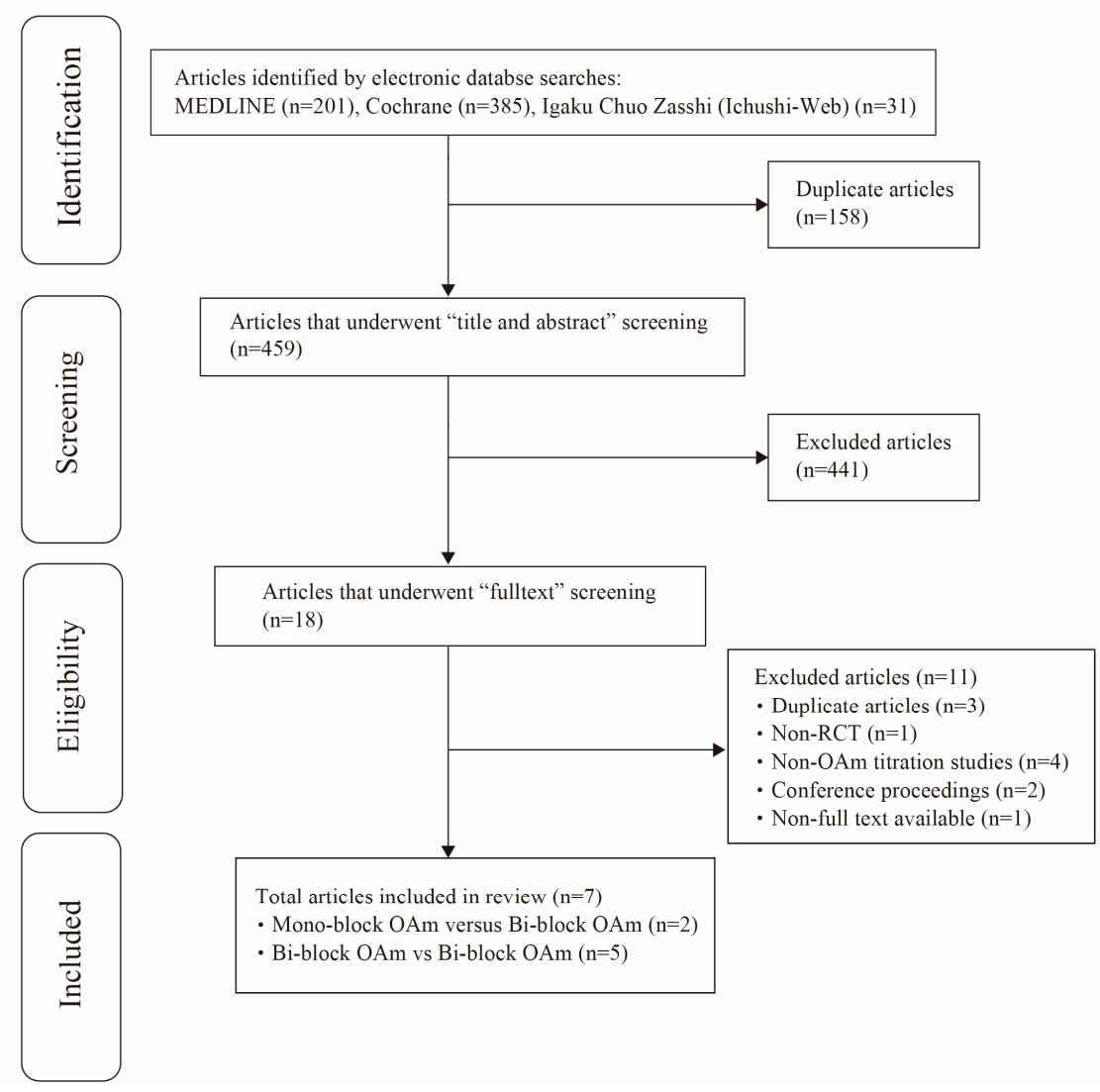

Figure 2. PRISMA flow diagram of selection process.

\subsection{Key Features of the Included Studies}

The main characteristics of the included studies are shown in Tables 1 and 2. Of the seven [15-21] articles accepted, six were randomized crossover studies [15-20] and one was a randomized parallel group comparison test [21]. There were six short-term follow-ups [15-20] and one long-term follow-up [21].

A risk of bias summary of randomized studies in Mono-block $\mathrm{OA}_{m}$ versus Bi-block $\mathrm{OA}_{m}$ according to Cochran's tool is shown in Figure 3. The study design adopted in two $[15,16]$ of the selected studies was a randomized crossover study, which we regarded as having high risk of performance bias. However, in the outcome evaluation of both reports, the bias had been judged to be small and thus we evaluated it as low risk. Another potential bias was that subsidies were granted as research funds [15]. However, since these were received by the university, we evaluated the case as having low risk of bias. A risk of bias summary of randomized studies in Bi-block $\mathrm{OA}_{m}$ versus Bi-block $\mathrm{OA}_{m}$ according to Cochran's tool is shown in Figure 4. The study design adopted in four out of five articles [17-21] was a randomized crossover study, which we regarded as having high risk of performance bias. Additionally, regarding attrition bias, a dropout was recorded in the middle of one study [20]. Since no ITT (intention-to-treat) analysis was conducted, we evaluated the case as having a high risk of case reduction bias. Another potential bias was that subsidies were granted as research funds [21]. However, since these were public funds, we evaluated the case as having low risk of bias. 
Table 1. Characteristics of the included studies for systematic review.

\begin{tabular}{|c|c|c|c|c|c|c|c|}
\hline Author & Study Design & Subjects & Interventions & Age & BMI & Follow-up & Outcomes \\
\hline \multicolumn{8}{|c|}{ Mono-block $\mathrm{OA}_{\mathrm{m}}$ vs Bi-block $\mathrm{OA}_{\mathrm{m}}$} \\
\hline Bloch 2000 & Cross over- RCT & 24 & $\begin{array}{l}\text { Mono-block } \\
\text { Herbst }\end{array}$ & $50.6 \pm 1.5^{\mathrm{a}}$ & $27.4 \pm 0.8^{\mathrm{a}}$ & $\begin{array}{l}(156 \pm 14 \text { days }) \\
\quad+1 \text { week }\end{array}$ & $\begin{array}{l}\text { AHI, ESS, Snoring (VAS), QOL, Side effect, Adherence, } \\
\text { Patients preference }\end{array}$ \\
\hline Zhou 2012 & Cross over- RCT & 16 & $\begin{array}{l}\text { Mono-block } \\
\text { SILENT NITE }\end{array}$ & $45.23(26.3-55.4)^{\mathrm{b}}$ & $26.67(22.3-29.8)^{\mathrm{b}}$ & 3 months & $\begin{array}{l}\text { AHI, ESS, Snoring Scale, Airway space, Side effect, Adherence, } \\
\text { Patient preference }\end{array}$ \\
\hline \multicolumn{8}{|c|}{ Bi-block $\mathrm{OA}_{\mathrm{m}}$ vs Bi-block $\mathrm{OA}_{\mathrm{m}}$} \\
\hline Lawton 2005 & Cross over- RCT & 16 & $\begin{array}{l}\text { Herbst } \\
\text { Twin Block }\end{array}$ & $44.8(24.0-68.4)^{\mathrm{c}}$ & $29.2(23.8-51.1)^{\mathrm{c}}$ & 4-6 weeks & $\begin{array}{l}\text { AHI, LowestspO2, ESS, Sleepiness (VAS), Snoring (VAS), SF-36, } \\
\text { Side effects }\end{array}$ \\
\hline Bishop 2014 & Cross over- RCT & 18 & $\begin{array}{c}\text { TAP } \\
\text { Klearway }\end{array}$ & $47.6 \pm 2.6^{a}$ & $31.4 \pm 1.0^{a}$ & $1-2$ months & RDI, ESS, SAQLI, Patient preference \\
\hline Ghazal 2009 & RCT & 103 & $\begin{array}{l}\text { IST } \\
\text { TAP }\end{array}$ & $55.5 \pm 10.6^{\mathrm{d}}$ & $25.9 \pm 2.9^{\mathrm{d}}$ & $\begin{array}{l}6 \text { months, } \\
24 \text { months }\end{array}$ & $\begin{array}{l}\text { AHI, LowestspO2, Arousal Index, Sleep stage, Sleep efficiency, } \\
\text { ESS, PSQI, SF-36, Adherence, Patient preference }\end{array}$ \\
\hline Rose 2002 & Cross over- RCT & 26 & $\begin{array}{c}\text { Silencer } \\
\text { Karwetzky activator } \\
\end{array}$ & $56.8 \pm 5.2^{d}$ & $27.5 \pm 3.1^{\mathrm{d}}$ & $6-8$ weeks & $\begin{array}{l}\text { RDI, LowestspO2, Sleepiness (VAS), Sleep quality (VAS), } \\
\text { Snoring (VAS), Adherence }\end{array}$ \\
\hline Gautheir 2009 & Cross over- RCT & 16 & $\begin{array}{l}\text { Silencer } \\
\text { Klearway }\end{array}$ & $56.8 \pm 5.3^{\mathrm{a}}$ & $25.9 \pm 2.1^{\mathrm{a}}$ & 3 months & $\begin{array}{l}\text { RDI, LowestspO2, Sleep stage, Sleep efficiency, Blood pressure, } \\
\text { ESS, FSS, FOSQ, Patient preference }\end{array}$ \\
\hline
\end{tabular}

$\mathrm{OA}_{\mathrm{m}}$ : Mandibular advancement type of oral appliance, AHI: Apnea-Hypopnia Index, ESS: Epworth Sleepiness Scale. RDI: Respiratory disturbance index, SAQLI: Sleep Apnea Quality of

Life Index, PSQI: Pittsburgh Sleep Quality Index. FSS: Fatigue Severity Scale, FOSQ: Functional Outcomes of Sleep Questionnaire. ${ }^{a}$ mean \pm SE, mean (SE). ${ }^{b}$ mean (minimum, maximum).

${ }^{c}$ median (quartile range). ${ }^{d}$ mean $\pm \mathrm{SD}$. 
Table 2. Continued.

\begin{tabular}{|c|c|c|c|c|c|c|c|}
\hline \multirow{2}{*}{ Study } & \multirow{2}{*}{ Interventions } & \multirow{2}{*}{ Follow Up } & \multicolumn{3}{|c|}{ AHI (RDI) } & \multirow{2}{*}{ Key Results } & \multirow{2}{*}{ Conclusion } \\
\hline & & & Baseline & wth $\mathrm{OA}_{\mathrm{m}}$ & \%Reuction & & \\
\hline \multicolumn{8}{|c|}{ Mono-block $\mathrm{OA}_{\mathrm{m}}$ vs Bi-blockOA $A_{m}$} \\
\hline \multirow{3}{*}{ Bloch 2000} & Mono-block & & $22.6 \pm 3.1^{\mathrm{a}}$ & $7.9 \pm 1.6^{\mathrm{a}}$ & 65.0 & \multirow{3}{*}{$\begin{array}{l}\text { Fifteen patients preferred the Monobloc, eight patients had } \\
\text { no preference, and one patient preferred the Herbst device }\end{array}$} & \multirow{3}{*}{$\begin{array}{l}\text { Both the Herbst and the Mono-bloc are effective therapeutic } \\
\text { devices for sleep apnea. The Mono-bloc relieved symptoms } \\
\text { to a greater extent than the OSA-Herbst, and was preferred by } \\
\text { the majority of patients on the basis of its simple application }\end{array}$} \\
\hline & & $156 \pm 14$ days & & & & & \\
\hline & Herbst & & $22.6 \pm 3.1^{\mathrm{a}}$ & $8.7 \pm 1.5^{\mathrm{a}}$ & 61.5 & & \\
\hline \multirow{3}{*}{ Zhou 2012} & Mono-block & \multirow{3}{*}{3 months } & $26.38 \pm 4.13^{b}$ & $6.58 \pm 2.28^{\mathrm{b} *}$ & 75.1 & \multirow{3}{*}{$\begin{array}{l}\text { The monoblock } \mathrm{OA}_{\mathrm{m}} \text { was statistically more efficient in } \\
\text { reducing AHI and Apnoea Index (AI) than the SILENT NITE } \\
\qquad(p<0.05)\end{array}$} & \multirow{3}{*}{$\begin{array}{l}\text { The Both OA } \mathrm{A}_{m} \text { showed good efficacy in the treatment for mild } \\
\text { to moderate OSA. Use of the monoblock appliance should be } \\
\text { considered when patients with OSA choose OA treatment, as } \\
\text { it was more efficient in reducing the AHI compared to the } \\
\text { two-piece appliance and was preferred by most patients. }\end{array}$} \\
\hline & & & & & & & \\
\hline & SILENT NITE & & $26.38 \pm 4.13^{\mathrm{b}}$ & $9.87 \pm 2.88^{\mathrm{b} *}$ & 62.6 & & \\
\hline \multicolumn{8}{|c|}{ Bi-block $\mathrm{OA}_{\mathrm{m}}$ vs Bi-block $\mathrm{OA}_{\mathrm{m}}$} \\
\hline \multirow{3}{*}{ Lawton 2005} & Twin Block & \multirow{3}{*}{ 4-6 weeks } & $45.5(29.0-68.0)^{\mathrm{c}}$ & $34.0(9.0-63.0)^{\mathrm{c}}$ & 25.3 & \multirow{3}{*}{$\begin{array}{l}\text { The Herbst } \mathrm{OA}_{\mathrm{m}} \text { proved to be the more effective appliance } \\
\text { for reducing daytime sleepiness }(p=0.04) \text { and was the more } \\
\text { popular appliance among the patients. }\end{array}$} & \multirow{3}{*}{$\begin{array}{l}\text { The Twin Block } \mathrm{OA}_{\mathrm{m}} \text { represents a viable alternative to the } \\
\text { Herbst } \mathrm{OA}_{\mathrm{m}} \text { in the treatment of patients with OSA. }\end{array}$} \\
\hline & & & & & & & \\
\hline & Herbst & & $45.5(29.0-68.0)^{\mathrm{c}}$ & $24.5(0.0-45.0)^{\mathrm{c}}$ & 46.2 & & \\
\hline \multirow{3}{*}{ Bishop 2014} & TAP & \multirow{3}{*}{$1-2$ months } & $16.5 \pm 3.2^{\mathrm{a}}$ & $7.7 \pm 3.3^{\mathrm{a}}$ & & \multirow{3}{*}{$\begin{array}{l}\text { There were no significant statistical differences in treatment } \\
\text { outcomes between the two appliances. There was a } \\
\text { statistically significant }(p<0.05) \text { preference for a OA } \mathrm{m} \text { design } \\
\text { with minimal coverage of teeth and palate. }\end{array}$} & \multirow{3}{*}{$\begin{array}{l}\text { There was a trend toward greater improvement with the } \\
\text { appliance with less acrylic resin bulk and less interocclusal } \\
\text { contact. OA selection should favor titratable, unobtrusive } \\
\text { designs with appropriate construction to promote acceptance } \\
\text { and adherence to OA therapy. }\end{array}$} \\
\hline & & & & & 53.3 & & \\
\hline & Klearway & & $16.5 \pm 3.2^{\mathrm{a}}$ & $10.3 \pm 3.2^{\mathrm{a}}$ & 37.6 & & \\
\hline \multirow{4}{*}{ Ghazal 2009} & IST & \multirow[b]{2}{*}{6 months } & $21.5 \pm 13.5^{b}$ & $11.1 \pm 11.8^{\mathrm{b} *}$ & & \multirow{4}{*}{$\begin{array}{l}\text { Quality of life, sleep quality, sleepiness, symptoms and sleep } \\
\text { outcome showed significant improvement in the short-term } \\
\text { evaluation with both appliances, but the TAP revealed a } \\
\text { significantly greater effect. After more than } 2 \text { years of } \\
\text { treatment, sleep outcomes revealed an equal effect with } \\
\text { both appliances. }\end{array}$} & \multirow{4}{*}{$\begin{array}{l}\text { This study illustrates that both the IST and the TAP } \\
\text { appliances are effective therapeutic devices for OSA after a } \\
\text { period of over } 24 \text { months. }\end{array}$} \\
\hline & & & $215+165$ & $67+91 b *$ & $\begin{array}{l}48.4 \\
68.8\end{array}$ & & \\
\hline & IST & \multirow{2}{*}{24 months } & $18.4 \pm 8.9^{b}$ & $4.6 \pm 5.8^{b}$ & 75.0 & & \\
\hline & TAP & & $19.8 \pm 12.7^{b}$ & $5.4 \pm 5.1^{\mathrm{b}}$ & 72.7 & & \\
\hline \multirow{3}{*}{ Rose 2002} & Silencer & \multirow{3}{*}{ 6-8 weeks } & $16.0(4.4)^{b}$ & $7.4(5.3)^{b *}$ & & \multirow{3}{*}{$\begin{array}{l}\text { The results showed that a statistically significant } \\
\text { improvement in the respiratory parameters was achieved } \\
\text { with both appliances }(p<0.01) \text {. However, the activator was } \\
\text { significantly more effective }(p<0.01) \text { than the Silencor. }\end{array}$} & \multirow{3}{*}{$\begin{array}{l}\text { Both appliances reduced daytime sleepiness and snoring and } \\
\text { improved sleep quality, and both influenced the treatment } \\
\text { outcome. }\end{array}$} \\
\hline & & & & & 53.8 & & \\
\hline & Karwetzky activator & & $16.2(4.6)^{\mathrm{b}}$ & $5.5(3.3)^{b *}$ & 66.0 & & \\
\hline & Silencer & & $10.0 \pm 1.2^{\mathrm{a}}$ & $4.7 \pm 0.9^{\text {a* }}$ & & & Although both $\mathrm{OA}_{\mathrm{m}}$ decreased $\mathrm{RDI}$ and subjective daytime \\
\hline Gautheir 2009 & & 3 months & & & 53.0 & $\begin{array}{l}\text { Ihe } \\
\text { subjects' waseference for comfort was in favor of the Klearway }\end{array}$ & $\begin{array}{l}\text { sleepiness in a similar manner, the choice between various } \\
\text { types of } O A_{m} \text { needs to be taken into account when }\end{array}$ \\
\hline & Klearway & & $10.0 \pm 1.2^{\mathrm{a}}$ & $6.5 \pm 1.3^{a^{*}}$ & 35.0 & & $\begin{array}{l}\text { subject compliance. } \\
\text { s. }\end{array}$ \\
\hline
\end{tabular}

$\mathrm{OA}_{\mathrm{m}}$ : Mandibular advancement type of oral appliance, AHI: Apnea hyapopnea index. ${ }^{a}$ mean $\pm \mathrm{SE}$, means (SE). ${ }^{\mathrm{b}}$ mean \pm SD. ${ }^{\mathrm{c}}$ median (quartile range). ${ }^{*} p<0.05$ : the comparion of two $\mathrm{OA}_{\mathrm{m}}$. 


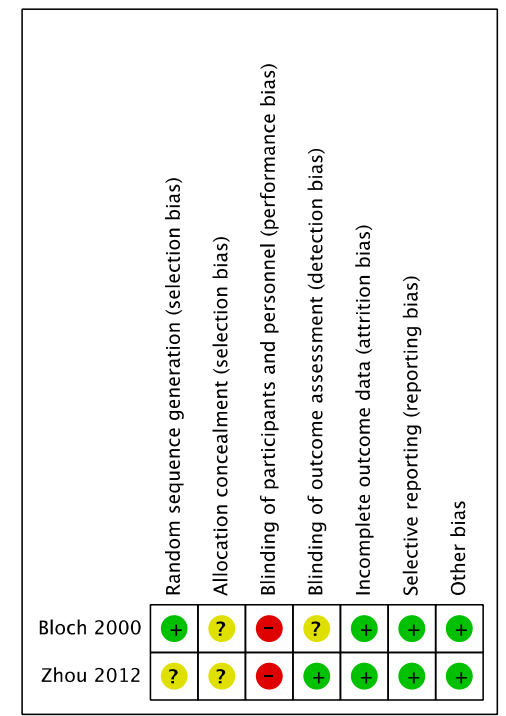

Figure 3. Assessment of risk of bias of the included studies (Mono-block $\mathrm{OA}_{\mathrm{m}}$ versus Bi-block $\mathrm{OA}_{\mathrm{m}}$ ) for systematic review.

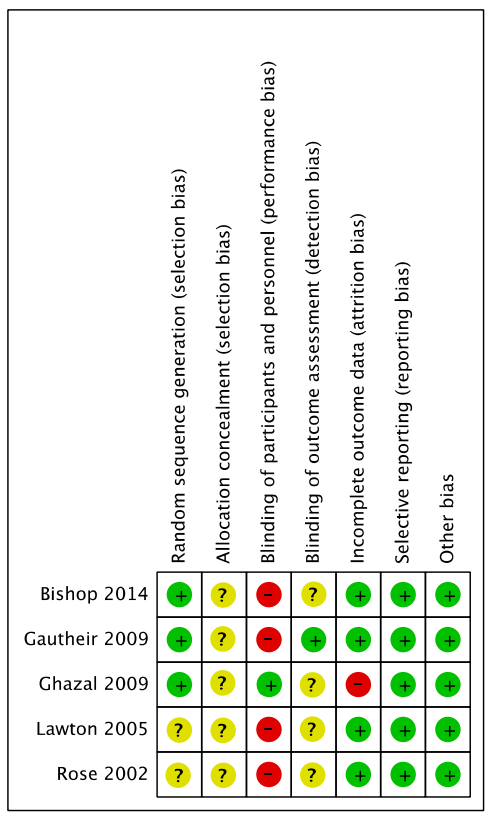

Figure 4. Assessment of risk of bias of the included studies (Bi-block $\mathrm{OA}_{m}$ versus Bi-block $\mathrm{OA}_{\mathrm{m}}$ ) for systematic review.

\subsection{Meta-Analysis}

Most of the articles included in this SR were short-term reports and there were no reports of mortality or cardiovascular events. We extracted and evaluated surrogate outcomes from included articles.

\subsubsection{Mono-Block $\mathrm{OA}_{\mathrm{m}}$ Versus Bi-Block $\mathrm{OA}_{\mathrm{m}}$}

The forest plots in the surrogate outcomes (AHI, lowest $\mathrm{SpO}_{2}$, arousal Index, NREM stage 3, sleep efficiency, ESS, Snoring Scale, side effects, patient preference) are shown in Figure 5. Comparing Mono-block $\mathrm{OA}_{\mathrm{m}}$ and Bi-block $\mathrm{OA}_{\mathrm{m}}$, Mono-block $\mathrm{OA}_{\mathrm{m}}$ significantly reduced $\mathrm{AHI}(2.92 ; 95 \% \mathrm{CI}$, 1.26 to $4.58 ; p=0.0006$ ), and patient preference for Mono-block $\mathrm{OA}_{\mathrm{m}}$ was significantly higher $(2.06 ; 95 \% \mathrm{CI}, 1.44$ to $2.06 ; p<0.0001)$. Lowest $\mathrm{SpO}_{2}$, arousal index, NREM stage 3, sleep efficiency, 
ESS, SS, and side effects were not significantly different between the two groups (favoring Mono-block $\mathrm{OA}_{\mathrm{m}}$, lowest $\mathrm{SpO}_{2}$ : $-11.18 ; 95 \% \mathrm{CI},-26.90$ to $4.54 ; p=0.16$; arousal index: $4.40 ; 95 \% \mathrm{CI},-6.00$ to 14.80 ; $p=0.41$, NREM stage 3: $-2.00 ; 95 \% \mathrm{CI},-6.00$ to $14.80 ; p=0.41$; sleep efficiency: $-1.42,95 \% \mathrm{CI},-4.71$ to $1.86 ; p=0.40$; ESS: $0.12 ; 95 \% \mathrm{CI},-1.55$ to $1.79 ; p=0.89 ; \mathrm{SS}: 0.55 ; 95 \% \mathrm{CI},-0.73$ to $1.83, p=0.55$; side effects: $1.00,95 \% \mathrm{CI}, 0.62$ to $1.61, p=1.00$ ).

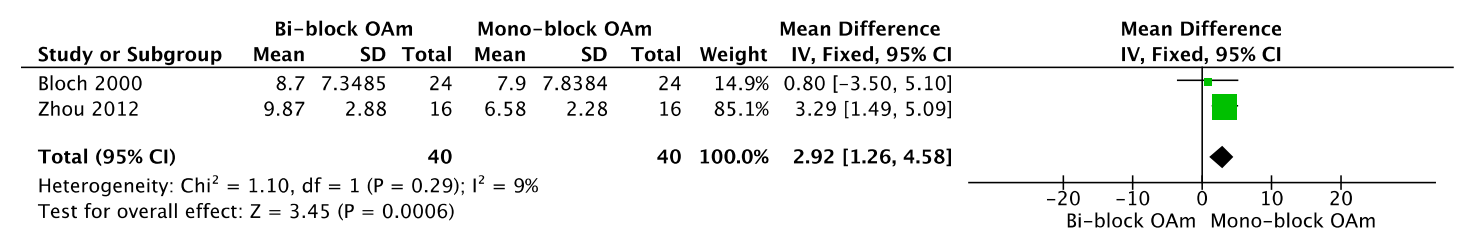

(A).

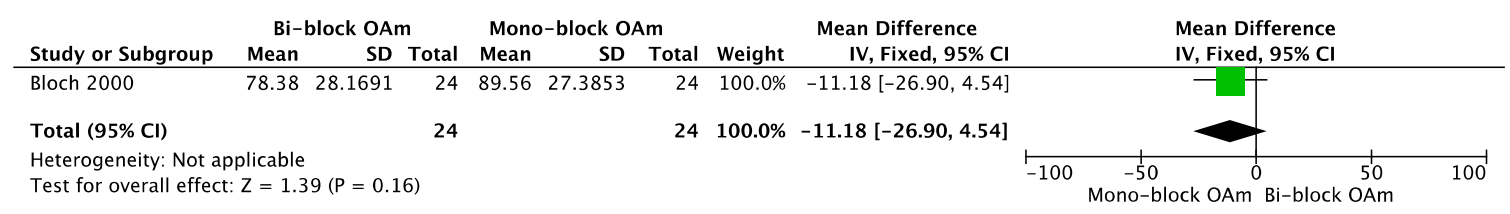

(B)

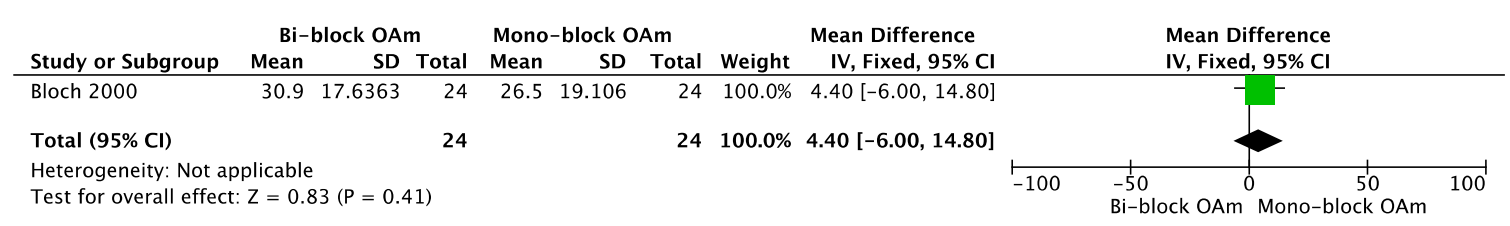

(C)

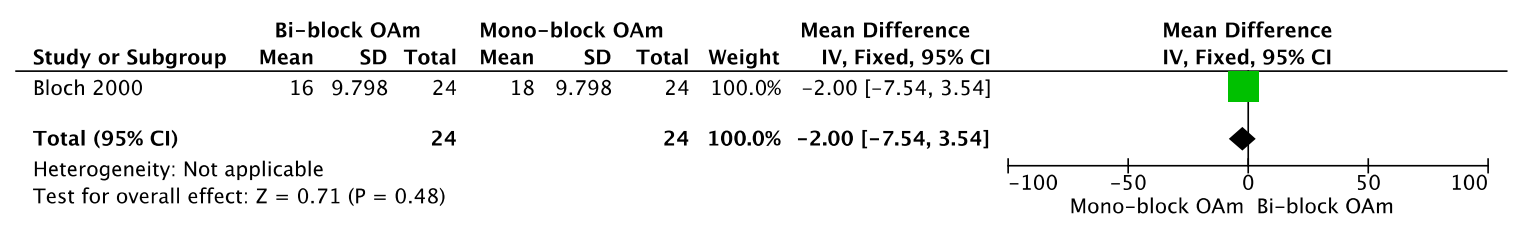

(D)

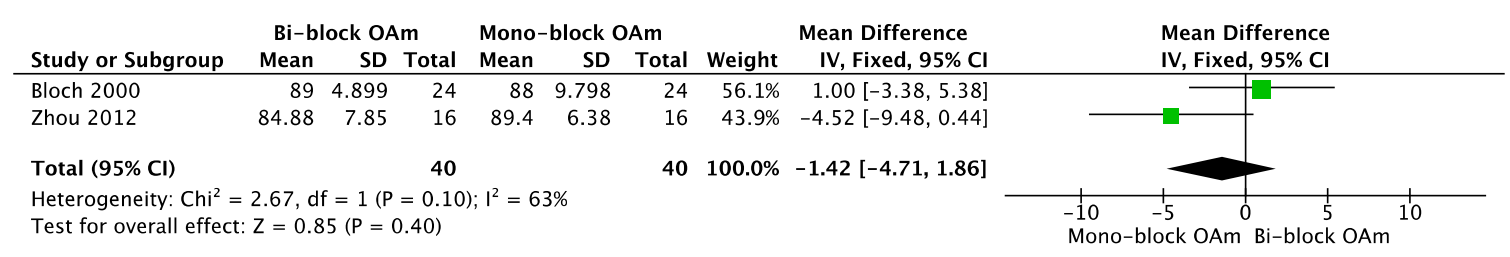

(E)

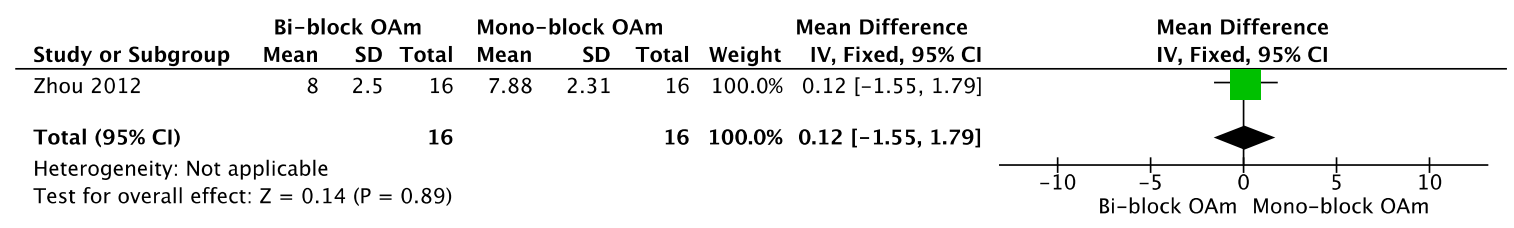

(F)

Figure 5. Cont. 


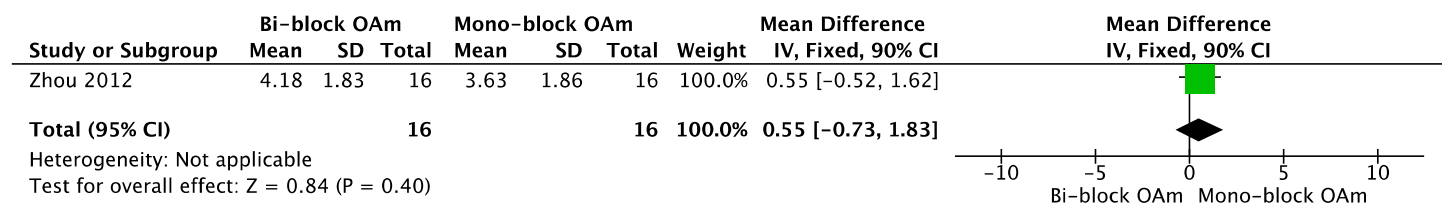

(G)

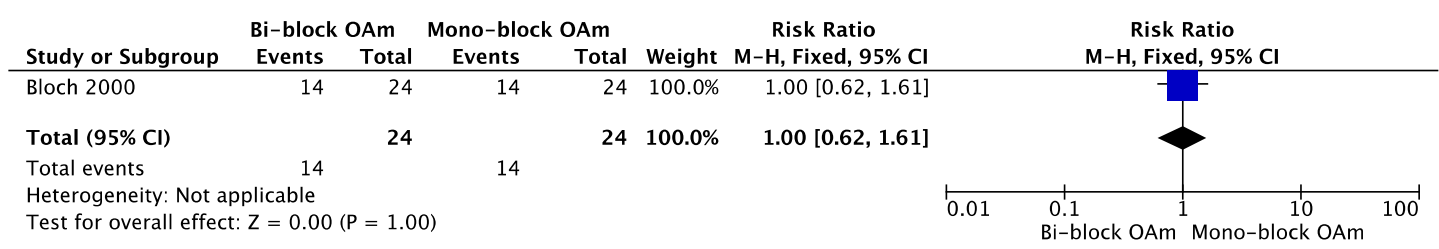

(H)

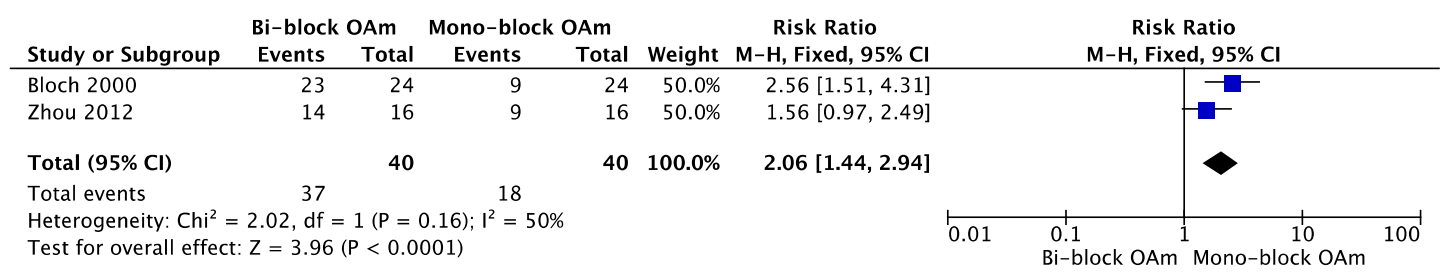

(I)

Figure 5. Forest plots of comparisons: Mono-block $\mathrm{OA}_{\mathrm{m}}$ versus Bi-block $\mathrm{OA}_{\mathrm{m}}$. Outcomes: (A) AHI, (B) Lowest $\mathrm{SpO}_{2}$, (C) Arousal Index, (D) Non-REM stage 3, (E) Sleep efficiency, (F) ESS, (G) Snoring Scale, (H) Side effects, (I) Patient preference. $\mathrm{OA}_{\mathrm{m}}$ : Mandibular advancement type of oral appliance, AHI: Apnea-Hypopnea Index, ESS: Epworth Sleepiness Scale.

\subsubsection{Bi-Block $\mathrm{OA}_{\mathrm{m}}$ Versus Bi-Block $\mathrm{OA}_{\mathrm{m}}$}

Although the study designs adopted in all five articles [17-21] were randomized controlled trials, various $\mathrm{OA}_{\mathrm{m}}$ devices were utilized, such as Herbst, Thornton Adjustable Positioner (TAP), Klearway, and IST models. Additionally, the material, thickness, and detailed design of each device differed, making it difficult to generate a comprehensive interpretation of results. Therefore, for this systematic review, no meta-analysis was performed regarding these five studies.

\subsection{GRADE Evidence Profile}

Table 3 provides the GRADE evidence profile. A funnel plot was not used to assess publication bias in this meta-analysis because the number of eligible articles was less than 10 . As a consequence of risk of bias, inconsistency, indirectness, imprecision, and other considerations, the overall quality of evidence for the AHI and patient preference was rated as low. The quality of evidence for the lowest $\mathrm{SpO}_{2}$, arousal index, NREM stage 3, sleep efficiency, ESS, Snoring Scale, and side effects was rated as very low. 
Table 3. GRADE evidence profile in the comparison of Mono-block OAm and Bi-block OAm.

\begin{tabular}{|c|c|c|c|c|c|c|c|c|c|c|c|}
\hline \multicolumn{7}{|c|}{ Certainty Assessment } & \multicolumn{2}{|c|}{ No. of Patients } & \multicolumn{2}{|r|}{ Effect } & \multirow{2}{*}{ Certainty } \\
\hline No. of Studies & $\begin{array}{l}\text { Study } \\
\text { Design }\end{array}$ & $\begin{array}{l}\text { Risk of } \\
\text { Bias }\end{array}$ & Inconsistency & Indirectness & Imprecision & $\begin{array}{c}\text { Other } \\
\text { Considerations }\end{array}$ & $\begin{array}{l}\text { Mono-Block } \\
\text { OA }_{m}\end{array}$ & $\begin{array}{c}\text { Bi-block } \\
\text { OA }_{m}\end{array}$ & $\begin{array}{l}\text { Relative } \\
(95 \% \text { CI) }\end{array}$ & $\begin{array}{l}\text { Absolute } \\
(95 \% \text { CI })\end{array}$ & \\
\hline \multicolumn{12}{|l|}{ AHI } \\
\hline \multirow{2}{*}{2} & \multirow{2}{*}{$\begin{array}{l}\text { randomised } \\
\text { trials }\end{array}$} & \multirow{2}{*}{ serious $^{a}$} & \multirow{2}{*}{ not serious } & \multirow{2}{*}{ not serious } & \multirow{2}{*}{ serious $^{b}$} & \multirow{2}{*}{ none } & \multirow{2}{*}{40} & \multirow{2}{*}{40} & \multirow{2}{*}{-} & MD 2.92 higher & \multirow{2}{*}{ LOW } \\
\hline & & & & & & & & & & (1.26 higher to 4.58 higher) & \\
\hline \multicolumn{12}{|l|}{ Lowest $\mathrm{SpO} 2$} \\
\hline \multirow{2}{*}{1} & \multirow{2}{*}{$\begin{array}{l}\text { randomised } \\
\text { trials }\end{array}$} & \multirow{2}{*}{ serious $^{a}$} & \multirow{2}{*}{ not serious } & \multirow{2}{*}{ not serious } & \multirow{2}{*}{ very serious ${ }^{b, c}$} & \multirow{2}{*}{ none } & \multirow{2}{*}{24} & \multirow{2}{*}{24} & \multirow[t]{2}{*}{-} & MD 11.18 lower & \multirow{2}{*}{ VERY LOW } \\
\hline & & & & & & & & & & (26.9 lower to 4.54 higher) & \\
\hline \multicolumn{12}{|l|}{ Arousal Index } \\
\hline 1 & randomised & serious a & not serious & not serious & very serious $b, c$ & none & 24 & 24 & - & MD 4.4 higher & VERY IOW \\
\hline & & & & & & & & & & (6 lower to 14.8 higher) & \\
\hline Non-REM Stage 3 & & & & & & & & & & & \\
\hline 1 & randomised & serious $^{\mathrm{a}}$ & not serious & not serious & very serious $b, c$ & none & 24 & 24 & - & MD 2 lower & VERY LOW \\
\hline & trials & & & & & & & & & (7.54 lower to 3.54 higher) & \\
\hline Sleep Efficiency & & & & & & & & & & & \\
\hline 2 & randomised & serious $\mathrm{a}^{\mathrm{a}}$ & corious $d$ & not serious & verv serious b,c & none & 40 & 40 & - & MD 1.42 lower & VERY LOW \\
\hline & & & & & & & & & & (4.71 lower to 1.86 higher) & \\
\hline ESS & & & & & & & & & & & \\
\hline 1 & randomised & serious $^{\mathrm{a}}$ & not serious & not serious & very serious ${ }^{b, c}$ & none & 16 & 16 & - & MD 0.12 higher & VERY LOW \\
\hline & trials & & & & & & & & & (1.55 lower to 1.79 higher) & \\
\hline Snoring Scale & & & & & & & & & & & \\
\hline 1 & randomised & serious $\mathrm{a}^{\mathrm{a}}$ & not serious & not serious & very serious b,c & none & 16 & 16 & - & MD 0.55 higher & VERY LOW \\
\hline & trials & & & & & & & & & (0.73 lower to 1.83 higher) & \\
\hline Side effect & & & & & & & & & & & \\
\hline 1 & randomised & serious a & not serious & not serious & very serious $b, c$ & none & $14 / 24$ & $14 / 24$ & RR 1.00 & 0 fewer per 1000 & VERY LOW \\
\hline & trials & & & & & & $(58.3 \%)$ & $(58.3 \%)$ & (0.62 to 1.61$)$ & (from 222 fewer to 356 more) & \\
\hline Patient preference & & & & & & & & & & & \\
\hline 2 & randomised & serious $^{\mathrm{a}}$ & not serious $\mathrm{e}$ & not serious & serious $b$ & none & $37 / 40$ & $18 / 40$ & RR 2.06 & 477 more per 1000 & LOW \\
\hline & trials & & & & & & $(92.5 \%)$ & $(45.0 \%)$ & (1.44 to 2.94$)$ & (from 198 more to 873 more) & \\
\hline
\end{tabular}

CI: Confidence interval, MD: Mean difference, RR: Risk ratio, AHI: Apnea Hypopnea Index, ESS: Epworth Sleepiness Scale. a. The risk of bias in included studies were high. b. The number of patients were very small. c. $95 \%$ CI contained no effect. d. Heterogeneity: $\mathrm{I}^{2}=63 \%$. e. Heterogeneity: $\mathrm{I}^{2}=50 \%$, but the direction of effect in two studies was same. f. Heterogeneity: $\mathrm{I}^{2}=66 \%$ 


\section{Discussion}

In this $\mathrm{SR}$, we investigated which designs were effective when performing $\mathrm{OA}_{\mathrm{m}}$ treatment for OSA patients. The primary outcome of successful OSA treatment is the improvement of life prognosis and the prevention of cardiovascular disease [22,23]. However, there were no reports of mortality or cardiovascular events in the included articles. The surrogate outcomes are often used, and there are many articles that have reported on surrogate outcomes. Therefore, in this systematic review, we analyzed the surrogate outcomes referred to in previous SRs $[6,10,24]$.

Several systematic reviews on the design of $\mathrm{OA}_{m}$ have been reported in the past [25-27]. Ahrens et al. [25,26] investigated the subjective patient outcome and polysomnographic indices. They concluded that there was no specific $\mathrm{OA}_{\mathrm{m}}$ design to improve the subjectively perceived treatment efficiency and the polysomnographic indices effectively. Serra-Torres et al. [27] showed that adjustable and custom-made $\mathrm{OA}_{m}$ have a better performance than fixed and prefabricated devices, and that Mono-block $\mathrm{OA}_{m}$ cause more adverse effects. However, the application of $\mathrm{OA}_{\mathrm{m}}$ used in the reports accepted for these systematic reviews did not include the titration of the lower jaw. In this systematic review, we targeted $\mathrm{OA}_{\mathrm{m}}$ for which titration (including adjustment) of the lower jaw was performed. As for the forward positioning of the lower jaw, many devices are set at 50-75\% of the maximum mandibular advancement amount [28,29]. However, a standardized value has yet to be established. Pulling the lower jaw forward expands the upper airway and increases treatment efficacy [30]. However, the burden on the temporomandibular joint, masticatory muscles, and teeth increase, which can lead to an increased risk of side effects such as temporomandibular disorders or tooth movement [31]. In clinical practice, it is necessary to perform the titration of the mandibular position after its initial fixation in order to strike a balance between treatment efficacy and side effects [32]. Therefore, the results of this systematic review can be considered to have high clinical significance.

There were only two studies comparing Mono-block $\mathrm{OA}_{\mathrm{m}}$ and Bi-block $\mathrm{OA}_{\mathrm{m}}$. Meta-analysis results showed that Mono-block $\mathrm{OA}_{m}$ were more effective in terms of $\mathrm{AHI}$ and patient preference values. During sleep, humans perform various jaw movements such as sleep bruxism and swallowing; however, for most of the time during sleep, the mouth remains open [33]. Generally, skeletal muscles relax and muscle tonus decreases during sleep [34]. The same phenomenon is observed for masticatory muscles, and it is assumed that the opening of the mouth is a result of the relaxation of muscles responsible for keeping the mouth closed [35]. It is assumed that in some cases, the tongue and soft palate retract with the opening of the mouth, which leads to a narrowing of the respiratory tract and resulting respiratory problems. Bi-block $\mathrm{OA}_{\mathrm{m}}$ contain various adjustment mechanisms to easily adjust the position of the lower jaw. Such layouts make it possible to open the mouth more or less freely. However, this also implies an increased chance of the lower jaw moving backward and downward during sleep. That is to say, the improvement of AHI values may be poor. On the other hand, with Mono-block $\mathrm{OA}_{\mathrm{m}}$, the upper and lower jaws are fixed in one position and mouth movement is often restricted. Therefore, as also reported by Bloch et al. [15] and Zhou et al. [16], AHI values improved at a better rate with Mono-block $\mathrm{OA}_{\mathrm{m}}$ compared to Bi-block $\mathrm{OA}_{\mathrm{m}}$.

There was also a report claiming that $\mathrm{AHI}$ values decreased significantly with Bi-block $\mathrm{OA}_{\mathrm{m}}$. It should be noted that the average BMI and AHI values differed from case to case. Ghazal et al. [20] reported a small decrease in AHI from $21.5 \pm 13.5$ to $11.1 \pm 11.8(48.4 \%$ decrease $)$ after using IST devices for six months $(n=47)$. However, after 24 months $(n=24)$, AHI values significantly improved, from $18.4 \pm 8.9$ to $4.6 \pm 5.8(75.0 \%$ decrease). Further, after six months of use of TAP devices for control $(n=48)$, AHI values significantly improved from $19.8 \pm 12.7$ to $6.7 \pm 9.1(68.8 \%$ decrease). After 24 months $(n=21)$, the device remained effective and AHI values improved significantly from $19.8 \pm 12.7$ to $5.4 \pm 5.1$ (72.7\% decrease). There are various types of Bi-block $\mathrm{OA}_{m}$; however, a collective opinion as to which design is most effective has not yet been formed. This systematic review only includes studies in which titration or post-adjustment comparison was performed. Regarding the AHI results, it was inferred that a large amount of mandibular advancement was set in the Mono-block $\mathrm{OA}_{\mathrm{m}}$ with complicated adjustment. Additionally, the capability of opening the mouth granted by 
Bi-block $\mathrm{OA}_{\mathrm{m}}$ was also considered to be a contributing factor. Further, the ESS, Snoring Scale, and side effects meta-analysis results showed no difference between Mono-block and Bi-block $\mathrm{OA}_{\mathrm{m}}$. Although no detailed descriptions concerning adherence were given, no differences were found. However, it should be noted that the patient preference values were higher for Mono-block $\mathrm{OA}_{\mathrm{m}}$. According to Bloch et al. [15], 15 out of 24 subjects (62.5\%) preferred Mono-block $\mathrm{OA}_{\mathrm{m}}$, whereas one subject $(6.7 \%)$ preferred the Herbst model, which is a Bi-block $\mathrm{OA}_{\mathrm{m}}$. The following reasons for the preference of Mono-block $\mathrm{OA}_{\mathrm{m}}$ were reported: greater alleviation of OSA symptoms $(n=11)$, robustness and ease of installation $(n=5)$, and less side effects $(n=4)$. The subject who preferred the Herbst model stated an impression of greater alleviation of OSA symptoms. Further, according to Zhou et al. [16], seven out of 16 subjects (43.8\%) preferred Mono-block $\mathrm{OA}_{\mathrm{m}}$, whereas two subjects $(12.5 \%)$ preferred the SILENT NITE model, which is a Bi-block $\mathrm{OA}_{\mathrm{m}}$. Although detailed reasons regarding preferences for each device were not clear, it was reported that six subjects experienced equipment failure with the SILENT NITE model during the study period, which may have contributed to the high number of subjects preferring Mono-block $\mathrm{OA}_{\mathrm{m}}$. It can be said that devices producing high patient preference values seem to satisfy not only in terms of therapeutic efficacy and side effect alleviation, but also the ease of installation and durability of the $\mathrm{OA}_{\mathrm{m}}$. Although Mono-block $\mathrm{OA}_{\mathrm{m}}$ evoke an image of severe constraint, this sense of constraint does not necessarily seem to be reflected in the patient preference values. In recently reported cases of OSA patients with locomotive syndrome and paralysis after a cerebral infarction [36], methods that allow for an easy installation seem to be preferred. In particular, Mono-block devices utilizing soft resin can be installed with only one hand. It seems that the choice of equipment also has to be considered in the context of each individual patient.

It should be noted that our systematic review was conducted under the following limitations. Firstly, a small sample size and limited number of studies were included in the review, with many reports covering only short research periods. Secondly, we included studies with a high risk of bias due to subject blind testing or incomplete data. Follow-up research will require a revised research design and greater sample size. In particular, $\mathrm{OA}_{\mathrm{m}}$ treatment is highly symptomatic and conducted over a long period of time, which necessitates further investigations of adherence and side effects.

\section{Conclusions}

Despite frequently small sample sizes and a majority of short-term reports, current evidence shows that Mono-block $\mathrm{OA}_{\mathrm{m}}$ are more effective than Bi-block $\mathrm{OA}_{\mathrm{m}}$ for OSA patients. Further well-designed, larger trials are required to determine the benefit for patients.

Author Contributions: H.I. and D.H. contributed to the study design; data collection, interpretation, and statistical analysis; and manuscript preparation. Y.S. contributed to the data collection, interpretation, and statistical analysis; and manuscript preparation. K.S. and H.Y. contributed to the study design; data collection, interpretation, and statistical analysis; and manuscript preparation. A.F. and E.K. contributed to data interpretation and manuscript preparation.

Funding: This work was supported by grants from The Japanese Academy of Dental Sleep Medicine.

Acknowledgments: We would like to thank Haruko Kobayashi, Library, Aichi Medical University for supporting the literature search of this systematic review.

Conflicts of Interest: The authors declare there is no conflict of interest regarding this study.

\section{References}

1. Young, T.; Palta, M.; Dempsey, J.; Skatrud, J.; Weber, S.; Badr, S. The occurrence of sleep-disordered breathing among middle-aged adults. N. Engl. J. Med. 1993, 328, 1230-1235. [CrossRef]

2. Flemons, W.W. Clinical practice. Obstructive sleep apnea. N. Engl. J. Med. 2002, 347, 498-504. [CrossRef] [PubMed]

3. Horner, R.L. Motor control of the pharyngeal musculature and implications for the pathogenesis of obstructive sleep apnea. Sleep 1996, 19, 827-853. [CrossRef] [PubMed] 
4. White, D.P. Pathogenesis of obstructive and central sleep apnea. Am. J. Respir. Crit. Care Med. 2005, 172, 1363-1370. [CrossRef] [PubMed]

5. Isono, S. Contribution of obesity and craniofacial abnormalities to pharyngeal collapsibility in patients with obstructive sleep apnea. Sleep Biol. Rhythms. 2004, 2, 17-21. [CrossRef]

6. Kushida, C.A.; Morgenthaler, T.I.; Littner, M.R.; Alessi, C.A.; Bailey, D.; Coleman, J., Jr.; Friedman, L.; Hirshkowitz, M.; Kapen, S.; Kramer, M.; et al. Practice parameters for the treatment of snoring and Obstructive Sleep Apnea with oral appliances: An update for 2005. Sleep 2005, 29, 240-243. [CrossRef] [PubMed]

7. Chan, A.S.; Sutherland, K.; Schwab, R.J.; Zeng, B.; Petocz, P.; Lee, R.W.; Darendeliler, M.A.; Cistulli, P.A. The effect of mandibular advancement on upper airway structure in obstructive sleep apnoea. Thorax 2010, 65, 726-732. [CrossRef]

8. Mehta, A.; Qian, J.; Petocz, P.; Darendeliler, M.A.; Cistulli, P.A. A randomized, controlled study of a mandibular advancement splint for obstructive sleep apnea. Am. J. Respir. Crit. Care Med. 2001, 163, 1457-1461. [CrossRef] [PubMed]

9. Gotsopoulos, H.; Chen, C.; Qian, J.; Cistulli, P.A. Oral appliance therapy improves symptoms in obstructive sleep apnea: A randomized, controlled trial. Am. J. Respir. Crit. Care Med. 2002, 166, 743-748. [CrossRef] [PubMed]

10. Ramar, K.; Dort, L.C.; Katz, S.G.; Lettieri, C.J.; Harrod, C.G.; Thomas, S.M.; Chervin, R.D. Clinical Practice Guideline for the Treatment of Obstructive Sleep Apnea and Snoring with Oral Appliance Therapy: An Update for 2015. J. Clin. Sleep Med. 2015, 11,773-827. [PubMed]

11. Chan, A.S.; Lee, R.W.; Cistulli, P.A. Dental appliance treatment for obstructive sleep apnea. Chest 2007, 132, 693-699. [CrossRef] [PubMed]

12. Atkins, D.; Best, D.; Briss, P.A.; Eccles, M.; Falck-Ytter, Y.; Flottorp, S.; Guyatt, G.H.; Harbour, R.T.; Haugh, M.C.; Henry, D.; et al. Grading quality of evidence and strength of recommendations. Br. Med. J. 2004, 328, 1490.

13. Guyatt, G.H.; Oxman, A.D.; Vist, G.E.; Kunz, R.; Falck-Ytter, Y.; Alonso-Coello, P.; Schünemann, H.J. GRADE: An emerging consensus on rating quality of evidence and strength of recommendations. Br. Med. J. 2008, 336, 924-926. [CrossRef] [PubMed]

14. Moher, D.; Liberati, A.; Tetzlaff, J.; Altman, D.G. Preferred Reporting ltems for Systematic Reviews and Meta-Analyses: The PRISMA Statement. Br. Med. J. 2009, 339, b2535. [CrossRef] [PubMed]

15. Bloch, K.E.; Iseli, A.; Zhang, J.N.; Xie, X.; Kaplan, V.; Stoeckli, P.W.; Russi, E.W. A Randomized, Controlled Crossover Trial of Two Oral Appliances for Sleep Apnea Treatment. Am. J. Respir. Crit. Care Med. 2000, 162, 246-251. [CrossRef] [PubMed]

16. Zhou, J.; Liu, Y.H. A randomised titrated crossover study comparing two oral appliances in the treatment for mild to moderate obstructive sleep apnoea/hypopnoea syndrome. J. Oral Rehabil. 2012, 39, 914-922. [CrossRef] [PubMed]

17. Bishop, B.; Verrett, R.; Girvan, T. A randomized crossover study comparing two mandibular repositioning appliances for treatment of obstructive sleep apnea. Sleep Breath. 2014, 18, 125-131. [CrossRef] [PubMed]

18. Lawton, H.M.; Battagel, J.M.; Kotecha, B. A comparison of the Twin Block and Herbst mandibular advancement splints in the treatment of patients with obstructive sleep apnoea: A prospective study. Eur. J. Orthod. 2005, 27, 82-90. [CrossRef] [PubMed]

19. Rose, E.; Staats, R.; Virchow, C.; Jonas, I.E. A comparative study of two mandibular advancement appliances for the treatment of obstructive sleep apnoea. Eur. J. Orthod. 2002, 24, 191-198. [CrossRef]

20. Ghazal, A.; Sorichter, S.; Jonas, I.; Rose, E.C. A randomized prospective long-term study of two oral appliances for sleep apnoea treatment. J. Sleep Res. 2009, 18, 321-328. [CrossRef]

21. Gauthier, L.; Laberge, L.; Beaudry, M.; Laforte, M.; Rompré, P.H.; Lavigne, G.J. Efficacy of two mandibular advancement appliances in the management of snoring and mild-moderate sleep apnea: A cross-over randomized study. Sleep Med. 2009, 10, 329-336. [CrossRef] [PubMed]

22. Martínez-García, M.A.; Soler-Cataluña, J.J.; Ejarque-Martínez, L.; Soriano, Y.; Román-Sánchez, P.; Illa, F.B.; Canal, J.M.; Durán-Cantolla, J. Continuous positive airway pressure treatment reduces mortality in patients with ischemic stroke and obstructive sleep apnea: A 5-year follow-up study. Am. J. Respir. Crit. Care Med. 2009, 180, 36-41. [CrossRef] [PubMed]

23. He, J.; Kryger, M.H.; Zorick, F.J.; Conway, W.; Roth, T. Mortality and apnea index in obstructive sleep apnea: Experience in 385 male patients. Chest 1988, 94, 9-14. [CrossRef] [PubMed] 
24. McDaid, C.; Griffin, S.; Weatherly, H.; Durée, K.; van der Burgt, M.; van Hout, S.; Akers, J.; Davies, R.J.; Sculpher, M.; Westwood, M. Continuous positive airway pressure devices for the treatment of obstructive sleep apnoea-hypopnoea syndrome: A systematic review and economic analysis. Health Technol. Assess. 2009, 13, 1-119. [CrossRef] [PubMed]

25. Ahrens, A.; McGrath, C.; Hägg, U. Subjective efficacy of oral appliance design features in the management of obstructive sleep apnea: A systematic review. Am. J. Orthod. Dentofac. Orthop. 2010, 138, 559-576. [CrossRef] [PubMed]

26. Ahrens, A.; McGrath, C.; Hägg, U. A systematic review of the efficacy of oral appliance design features in the management of obstructive sleep apnea. Eur. J. Orthod. 2011, 33, 318-324. [CrossRef] [PubMed]

27. Serra-Torres, S.; Bellot-Arcís, C.; Montiel-Company, J.M.; Marco-Algarra, J.; Almerich-Silla, J.M. Effectiveness of mandibular advancement appliances in treating obstructive sleep apnea syndrome: A systematic review. Laryngoscope 2016, 126, 507-514. [CrossRef]

28. Clark, G.T. Mandibular advancement devices and sleep disordered breathing. Sleep Med. Rev. 1998, 2, $163-174$. [CrossRef]

29. Sutherland, K.; Vanderveken, O.M.; Tsuda, H.; Marklund, M.; Gagnadoux, F.; Kushida, C.A.; Cistulli, P.A. Oral appliance treatment for obstructive sleep apnea: An update. J. Clin. Sleep Med. 2014, 10, $215-227$. [CrossRef]

30. Almeida, F.R.; Tsuiki, S.; Hattori, Y.; Takei, Y.; Inoue, Y.; Lowe, A.A. Dose-dependent effects of mandibular protrusion on genioglossus activity in sleep apnoea. Eur. Respir. J. 2011, 37, 209-212. [CrossRef]

31. Aarab, G.; Lobbezoo, F.; Hamburger, H.L.; Naeije, M. Effects of an oral appliance with different mandibular protrusion positions at a constant vertical dimension on obstructive sleep apnea. Clin. Oral. Investig. 2010, 14, 339-345. [CrossRef] [PubMed]

32. Hamoda, M.M.; Kohzuka, Y.; Almeida, F.R. Oral Appliances for the Management of OSA: An Updated Review of the Literature. Chest 2018, 153, 544-553. [CrossRef] [PubMed]

33. Kato, T.; Thie, N.M.; Montplaisir, R.; Lavigne, G.J. Bruxism and Orofacial movements during sleep. Dent. Clin. North Am. 2001, 45, 657-684. [PubMed]

34. Kato, T.; Montplaisir, J.Y.; Guitard, F.; Sessle, B.J.; Lund, J.P.; Lavigne, G.J. Evidence that experimentallyinduced sleep bruxism is a consequence of transient arousal. J. Dent. Res. 2003, 82, 284-288. [CrossRef] [PubMed]

35. Tangel, D.J.; Mezzanotte, W.S.; Sandberg, E.J.; White, D.P. Influences of NREM sleep on the activity of tonic vs. inspiratory phasic muscles in normal men. J. Appl. Physiol. 1992, 73, 1058-1066. [CrossRef]

36. Kataoka, H.; Miyatake, N.; Ichikawa, H.; Arakawa, Y.; Mori, Y. Sub-analysis of the prevalence of locomotive syndrome and its relationship with health-related quality of life in patients with obstructive sleep apnea syndrome as classified by age and sex. Sleep Biol. Rhythm. 2019, 17, 149-153. [CrossRef] 